\title{
Isolation and Characterization of Lathyrus odoratus Lectins and Their Agglutinating Activity against Chicken Erythrocytes
}

\author{
Masaki SaKakibara, Hajime NoguChI and Shio MaKino \\ Department of Food Science and Technology, Faculty of Agriculture, \\ Nagoya University, Nagoya, Japan \\ Received December 5, 1978
}

\begin{abstract}
Three kinds of lectins (LOL-I, II and III) were isolated from seeds of Lathyrus odoratus (sweet pea) in a homogenous form. The three fractions agglutinated the erythrocytes of laying hens, and the agglutination was strongly inhibited by a-methyl D-mannoside and Dmannose. However, they did not agglutinate those of the males and nonlyaing hens, differing from concanavalin A which showed a similar binding specificity for monosaccharide to LOL and agglutinated all types of erythrocytes derived from chicken in this study. LOL-I and II had a molecular weight of 52,000 and both consisted of two large $(20,000$ daltons) and two small subunits (6000 daltons). LOL-III had a molecular weight of 55,000, and its subunit structure was different from those of LOL-I and II. The amino acid compositions of the three fractions were very similar. They contained large amounts of aspartic acid, threonine, serine and valine, but no cysteine or methionine. Circular dichroism measurements indicated that $\beta$-structure was a major secondary structure of these lectins. The addition of $\alpha$-methyl Dmannoside or $\mathrm{D}$-mannose had significant effects on the $\mathrm{CD}$ spectra in the near-ultraviolet region, but no detectable change was observed in the $200 \sim 250 \mathrm{~nm}$ region. LOL-I had two binding sites for D-mannose, and the association constant was about 1000 liters per mol.
\end{abstract}

Proteins which agglutinate erythrocytes can be isolated from many plant seeds. ${ }^{1,2)}$ These proteins, known as plant lectins, are demonstrated to be specific reagents for use in studies on the distribution of saccharide on cell surfaces. ${ }^{3)}$

There is some evidence that the structure and the protein composition of chicken erythrocyte membrane change during differentiation and laying. ${ }^{4,6)}$ A crude extract from the seeds of Lathyrus odoratus is capable of agglutinating the erythrocyte of laying hens and embryos, but not the males on nonlaying hens. ${ }^{5)}$ Therefore, an elucidation of the mechanism of agglutination will lead to some insights regarding the alteration in cell surface structure during differentiation and laying. Basic information on the molecular characteristics of the lectin, including its size, subunit structure and number

\footnotetext{
Abbreviations. Con A, concanavalin A; PAGE, polyacrylamide gel electrophoresis; SDS-PAGE, polyacrylamide gel electrophoresis in the presence of sodium dodecyl sulfate; LOL, Lathyrus odoratus lectin; $\mathrm{CD}$, circular dichroism; DMS, dimethyl suberimidate.
}

of binding sites, is required for understanding the mechanism of agglutination.

This paper reports on the molecular characteristics of lectins from Lathyrus odoratus and then describes some qualitative findings on the difference in agglutinating activities against chicken erythrocytes between Lathyrus odoratus lectins and concanavalin $\mathrm{A}$, which have a very similar binding ability to that of sugars.

\section{MATERIALS AND METHODS}

Materials. The chicken erythrocyte was kindly supplied by Dr. K. Kondo, Department of Animal Science, Nagoya University. The inbred strain of chicken, New Hampshire, was used in this study. Concanavalin A (Con A, obtained from Sigma) was repurified by affinity chromatography of maltoseconjugated aminoethyl Bio-Gel P-100 column. ${ }^{7)}$ The proteins used for the calibration of polyacrylamide gel electrophoresis (PAGE) and gel filtration were obtained from commercial sources and were electrophoretically pure. All other chemicals used were of reagent grade.

Preparation of Lathyrus odoratus lectin (LOL). Finely powdered Lathyrus odoratsu seeds $(100 \mathrm{~g})$ were suspended in $500 \mathrm{ml}$ of water and stirred for $12 \mathrm{hr}$ at 
$4^{\circ} \mathrm{C}$. The insoluble material was removed by centrifugation at $8000 \mathrm{rmp}$ for $30 \mathrm{~min}$. The supernatant was exhaustively dialyzed against sodium phosphate buffer (ionic strength, $0.01 ; \mathrm{pH} 7.0$ ) at $4^{\circ} \mathrm{C}$. After the removal of precipitate formed during dialysis by centrifugation, the supernatant was applied to a Sephadex G-100 column which was equilibrated with the same phosphate buffer. The column was washed with the same phosphate buffer until the absorption at $280 \mathrm{~nm}$ reached the value of baseline. LOL was then eluted with $0.1 \mathrm{M}$ D-glucose dissolved in the same phosphate buffer. The eluant from the Sephadex column was applied to a DEAE-cellulose column after exhaustive dialysis against $0.01 \mathrm{M}$ Tris- $\mathrm{HCl}$ buffer $(\mathrm{pH} 7.2)$, and three fractions (LOL-I, II and III) were isolated by $\mathrm{NaCl}$ gradient as shown in Fig. 1. Pooled fractions, represented by bars in the figure were used for the following experiments.

Polyacrylamide gel electrophoresis and estimation of molecular weight. Disc electrophoresis was carried out in $7.5 \%$ gels at $\mathrm{pH} 8.3$ by the method of Ornstein and Davis. ${ }^{8)}$ PAGE in the presence of $8 \mathrm{M}$ urea $(8 \mathrm{M}$ urea-PAGE) was performed in $7.5 \%$ gels at $\mathrm{pH} 8.3$ in essentially the same manner as described above. PAGE in the presence of sodium dodecyl sulfate (SDSPAGE) was carried out by the method of Weber and Osborn $^{\text {2) }}$ at several concentrations of acrylamide containing $0.1 \% \mathrm{SDS}$, and no anomalous migration of lectin was found in Ferguson plot. ${ }^{10)}$ To estimate molecular weights of protein smaller than 10,000 , gel electrophoresis was run in $12.5 \%$ polyacrylamide gels containing $0.1 \%$ SDS in accordance with the method described by Swank and Munkers. ${ }^{11)}$ Gel staining was performed with coomassie brilliant blue $\mathbf{R}$ for all experiments. Standard proteins used for the estimation of molecular weight were: aldolase, chymotrypsinogen, soybean trypsin inhibitor, aprotinin and insulin $B$ chain (Boehringer Mannheim); bovine serum albumin, ovalbumin and cytochrome C (Sigma), and myoglobin (Seikagaku Kogyo). Since there were some doubts about molecular weights less than 10,000 determined by SDS-PAGE, ${ }^{11}$ the molecular weight estimation for small polypeptides was also performed by gel filtration in $2 \mathrm{mM}$ sodium phosphate buffer ( $\mathrm{pH} 7.0$ ) containing $7 \mathrm{M}$ urea and $0.15 \mathrm{M} \mathrm{NaCl}$ on Sephadex G-75. Calibration proteins were: myoglobin, cytochrome $\mathrm{C}$, aprotinin, insulin $\mathrm{A}$ and $\mathrm{B}$ chains. To avoid or minimize the formation of cyanate, the urea solutions were freshly made and filtered through a mixed resin immediately before use, and the fractionation was carried out at $4^{\circ} \mathrm{C}$.

Extinction coefficient. Extinction coefficient, $E_{1 \mathrm{~cm}}^{1 \%}$ at $280 \mathrm{~nm}$, was determined in two mutually independent ways, dry weight method and amino acid analysis. ${ }^{12}$ ) The sample solution was exhaustively dialyzed against distilled water. The absorbance at $280 \mathrm{~nm}$ of the sample solution was measured with a Hitachi Model 356 two-wavelength double beam spectrophotometer. The dry weight of protein $(c a .10 \mathrm{mg}$ ) was determined by drying the solution at $107^{\circ} \mathrm{C}$ in a vacuum oven to a constant weight. By the latter method, samples of known volumes and absorbances were hydrolyzed in $6 \mathrm{~N} \mathrm{HCl}$ at $110^{\circ} \mathrm{C}$ and subsequently analyzed on an amino acid analyzer (see below). The weight of the protein sample was determined by amino acid analysis of a hydrolysate. The value was corrected by the yield of amino acid analysis of the reference protein (lysozyme), which was analyzed at the same time in order to be quantitatively related to the original weight.

Ultracentrifuge studies. The ultracentrifugal anaiysis was performed on an analytical ultracentrifuge Hitachi Model UCA-01 in $0.2 \mathrm{M} \mathrm{KCl,} 2 \mathrm{~mm}$ sodium phosphate buffer, $\mathrm{pH} 7.0$. Sedimentation velocity was measured at four different protein concentrations by a schlieren optical system, and sedimentation coefficient was determined by extrapolation to zero concentration. Sedimentation equilibrium studies were performed by the use of a photoelectric scanner system in accordance with the method of Yphantis. ${ }^{13)}$ The partial specific volume was determined on the basis of the solution densities which were measured with a precision densitimeter Anton Paar DMA 02C.

Isoelectric focusing. Isoelectric focusing was done in acrylamide gels containing $2 \%(\mathrm{w} / \mathrm{v}) \mathrm{pH} 3$ to 10 Ampholines (LKB Produkter, Sweden). The proteins were stained with coomassie brilliant blue $\mathrm{G}$. The $\mathrm{pH}$ gradient established after isoelectric focusing was measured in blank gels by slicing the gels transversely into $3 \mathrm{~mm}$ sections, eluting the Amphilites into $1.0 \mathrm{ml}$ of degassed water and determining the $\mathrm{pH}$ of the solution.

Cross-linking experiments. Cross-linking with dimethyl suberimidate (DMS, obtained from Nakarai Chemicals) was performed by the procedure of Davis and Stark. ${ }^{14)}$ Immediately before use, DMS was dissolved in $0.1 \mathrm{M}$ trimethanolamine-HCl buffer, $\mathrm{pH} 8.5$. Aliquots of this solution were added to an equal volume of protein solution, ranging from 1 to $4 \mathrm{mg}$ per $\mathrm{ml}$. After incubation for $2 \mathrm{hr}$ at $4^{\circ} \mathrm{C}$, the reaction mixture was dialyzed against sodium phosphate buffer (ionic strength $0.01, \mathrm{pH} 7.0$ ), and the protein was analyzed by SDS-PAGE. For estimation of protein contents in various bands, gels were scanned for dye absorbance with a Shimadzu dual-wavelength TLC scanner CS-910.

Amino acid analysis. Samples were hydrolyzed in distilled $6 \mathrm{~N} \mathrm{HCl}$ at $110^{\circ} \mathrm{C}$ for 22,44 and $66 \mathrm{hr}$ in sealed tubes. Amino acid analyses were run on a JEOL JLC-6AH amino acid analyzer with a computing integrator.

Carbohydrate analysis. Neutral sugar was analyzed 
by the phenol-sulfuric acid method with D-glucose as standard.15) For identification of neutral sugars as alditol-acetates, gas chromatography was performed. ${ }^{1}{ }^{1}$ ) Samples for this assay were hydrolyzed with $1 \mathrm{~N} \mathrm{H}_{2} \mathrm{SO}_{4}$ at $100^{\circ} \mathrm{C}$ for $6 \mathrm{hr}$. Analysis of amino sugar was achieved by the method of Elson and Morgan with $N$-acetyl glucosamine as standard. ${ }^{17}$ )

Circular dichroism $(C D) . \quad \mathrm{CD}$ measurements were carried out at $23^{\circ} \mathrm{C}$ in a $J A S C O$ model $J-40 A$ recording spectropolarimeter. The spectra were obtained from cells of 1 and $10 \mathrm{~mm}$ path lengths for the ranges $195 \sim$ 300 and $250 \sim 350 \mathrm{~nm}$, respectively. The protein concentration was $0.3 \sim 1.2 \mathrm{mg} / \mathrm{ml}$. Mean residue molecular weight was calculated from the amino acid composition.

Assay of hemagglutinating activity. Hemagglutinating activity was assayed in $0.14 \mathrm{M} \mathrm{NaCl}, 0.01 \mathrm{M}$ sodium phosphate buffer ( $\mathrm{pH}$ 7.2). The lectin solutions to be tested were diluted in 2-hold dilution series. Erythrocytes were washed 3 times with the above buffer, and a $2 \%$ suspension was used. For this test, $0.5 \mathrm{ml}$ of erythrocyte suspension was added to an equal volume of the lectin solution. The mixture was kept for $12 \mathrm{hr}$ at $4^{\circ} \mathrm{C}$ and observed macroscopically. The titer was defined as the reciprocal of the dilution at the point of the minimum concentration necessary to show visible hemagglutination.

Inhibition assays were carried out by the method of Matsumoto and Osawa. ${ }^{18)}$ For this test, $0.05 \mathrm{ml}$ of 2-fold dilution series of each sugar solution was added to an equal volume of lectin solution 4 times more concentrated than the solution allowing the first perceptible hemagglutination. After incubation for $2 \mathrm{hr}$ at room temperature, $0.1 \mathrm{ml}$ of $2 \%$ erythrocyte suspen- sion was added to the lectin-sugar solution. The mixture was kept for $12 \mathrm{hr}$ at $4^{\circ} \mathrm{C}$ and then examined for agglutination.

Equilibrium dialysis. Equilibrium dialysis was performed with an acrylic plastic cell of $100 \mu l$ volume in each chamber. Dialysis membranes were cut from Visking dialysis tubing type 20/32, boiled in $1 \%$ $\mathrm{NaHCO}_{3}$ containing $1 \mathrm{~mm}$ EDTA and exhaustively washed with distilled water before use. In each experiment, 60 to $70 \mu$ of LOL-I solution $(\sim 40 \mathrm{mg} / \mathrm{ml})$ and $\mathrm{D}$-mannose solutions containing ${ }^{3} \mathrm{H}$-labeled sugar (D- $\left[2-{ }^{3} \mathrm{H}\right]$ mannose, obtained from Amersham, England) were placed in the opposite compartments to the dialysis cells. The cells were gently rotated for 24 hr at $4^{\circ} \mathrm{C}$. From each compartment, 10 or $20 \mu \mathrm{l}$ samples were then removed, mixed with $5 \mathrm{ml}$ of a Triton X-100toluene scintillation liquid, and the radioactivity in each sample was measured in an Aloka scintillation spectrometer LSC-671.

\section{RESULTS}

\section{Preparation and homogeneity of LOL-I, II and III}

Affinity chromatography of crude LOL from $100 \mathrm{~g}$ of seeds on Sephadex G-100 yielded ca. $90 \mathrm{mg}$ of lectin. Disc electrophoresis and isoelectric focusing of this material revealed three protein bands. Separation of the three fractions was achieved by ion-exchange chromatography on DEAE-cellulose (Fig. 1), and each component was found homogeneous by the

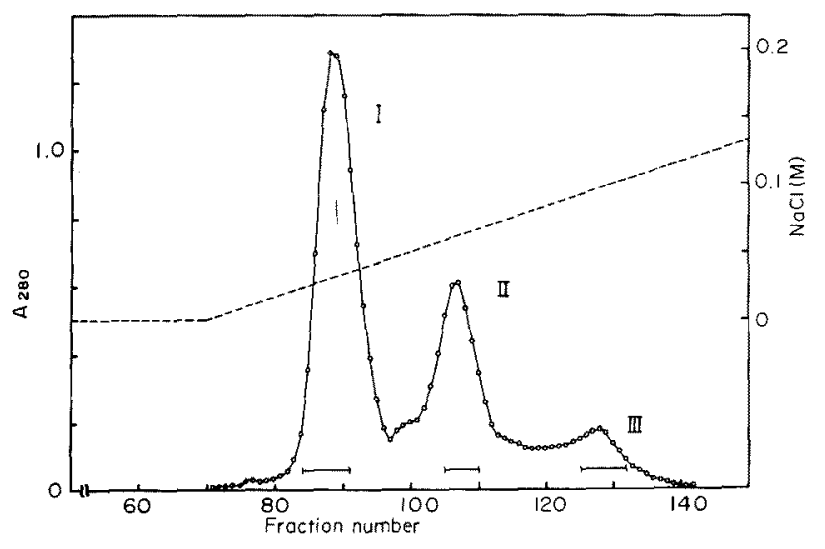

Fig. 1. DEAE-cellulose Column Chromatography of Affinity-purified LOL.

LOL (60 mg) was applied to a DE52 cellulose column $(2.2 \times 20 \mathrm{~cm}$ ) (Whatman), equilibrated with $0.01 \mathrm{M}$ Tris-HCl buffer ( $\mathrm{pH} 7.2$ ). Bound material was eluted with a $500 \mathrm{ml}$ linear gradient from 0 to $0.3 \mathrm{M} \mathrm{NaCl}$ in the same buffer at a flow rate of $20 \mathrm{ml} / \mathrm{hr}$ at $4^{\circ} \mathrm{C}$, and $4.2 \mathrm{ml}$ fractions were collected. - $-\mathrm{A}_{230} ;------, \mathrm{NaCl}$ concentration. 


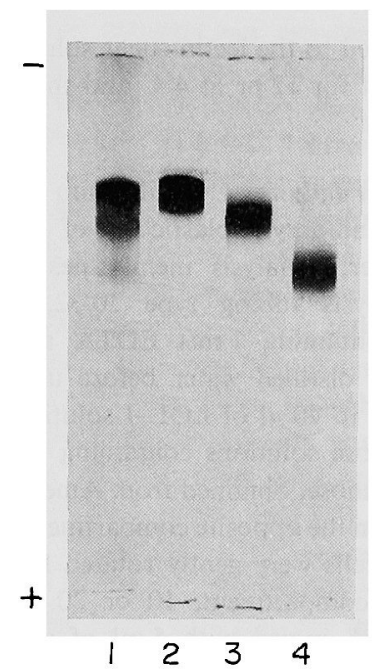

FIG. 2. Disc Electrophoresis of Affinity-purified LOL, LOL-I, II and III.

Disc electrophoresis was carried out at $\mathrm{pH} 8.3$. (1) Affinity-purified LOL, (2) LOL-I, (3) LOL-II, (4) LOL-III.

criteria of disc electrophoresis (Fig. 2), isoelectric focusing (Fig. 3) and ultracentrifugation. The most abundant component was LOL-I (pI 6.6) which was twice as great as the more acidic component LOL-II (pI 5.8). The remainder was the most acidic component LOL-III (pI 4.9) which accounted for about $10 \%$ of total LOL.

The lectins were stable in $0.14 \mathrm{M} \mathrm{NaCl}$, $0.01 \mathrm{M}$ sodium phosphate buffer, $\mathrm{pH} 7.0$ (protein concentration 0.1 to $3.0 \mathrm{mg} / \mathrm{ml}$ ) for at least one month as determined by the assay of agglutinating activity. However, storage of the proteins in a freeze-dried powder form induced the occurrence of insoluble materials which were soluble only in denaturing solvent.

\section{Extinction coefficients}

Extinction coefficients, $E_{1 \mathrm{~cm}}^{1 \%}$ at $280 \mathrm{~nm}$, of three components are listed in Table I. Consistent values were obtained by two methods, dry weight and amino acid analysis.

\section{Ultracentrifuge studies}

Ultracentrifugation of lectins yielded a single symmetrical peak during the entire course of run, and there was no significant effect of pro-
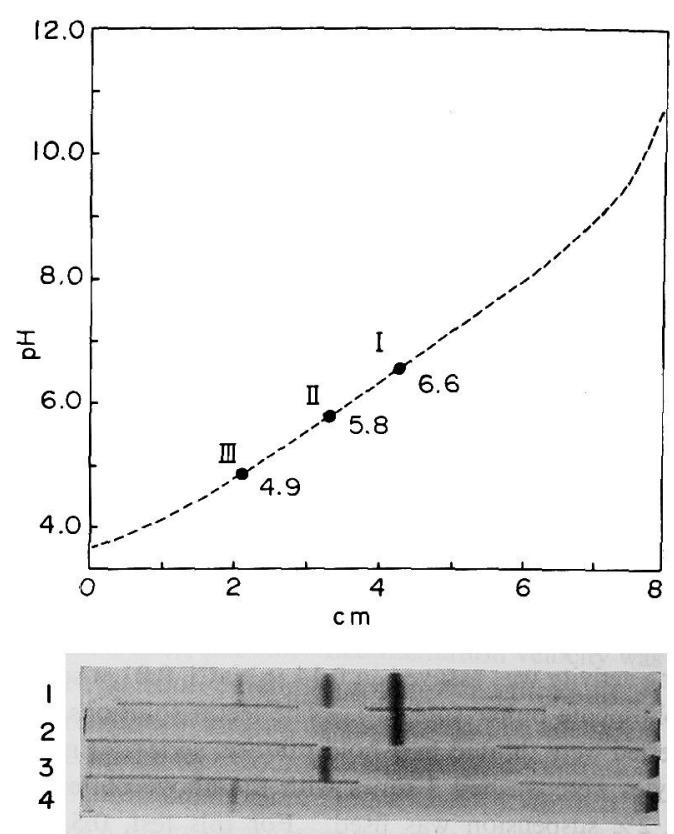

FIG. 3. Isoelectric Focusing of Affinity-purified LOL, LOL-I, II and III.

Isoelectric focusing was done on a $\mathrm{pH} 3$ to 10 Ampholine gradient in $5 \%$ polyacrylamide gel. The broken line indicates $\mathrm{pH}$ gradient. (1) Affinity-purified LOL, (2) LOL-I, (3) LOL-II (4) LOL-III.

tein concentration on the sedimentation coefficient in the range of 2 to $8 \mathrm{mg}$ per $\mathrm{ml}$. Sedimentation equilibrium measurements for LOL-I and LOL-III gave linear Yphantis plots, which also indicate homogeneity of the proteins. The molecular weights and the sedimentation coefficients are listed in Table I.

\section{Dissociation into subunits and their molecular weight}

Dissociation into subunits was accomplished only by the aid of denaturing reagents, i.e., urea, SDS and guanidine hydrochloride. Removal of denaturants by dialysis led the proteins to precipitation and failed to restore the native conformation.

The molecular weight of each subunit was estimated by SDS-PAGE or sometimes, by gel filtration in $7 \mathrm{M}$ urea. No difference was observed in SDS-PAGE whether or not a reducing reagent, 2-mercaptoethanol, was used. Typical results of SDS-PAGE and $8 \mathrm{M}$ urea- 
Table I. Physico-chemical Properties of LOL-I, II and III

\begin{tabular}{lccr}
\multicolumn{1}{c}{ Property } & LOL-I & LOL-II & LOL-III \\
\hline $\begin{array}{l}\text { Extinction coefficient } \\
\left(E_{1 \mathrm{~cm}}^{1 \%} \text { at } 280 \mathrm{~nm}\right)^{a}\end{array}$ & $12.7(12.7)$ & $13.3(13.1)$ & $133(128)$ \\
$\begin{array}{l}\text { Isoelectric point } \\
(\mathrm{PI})\end{array}$ & 6.6 & 5.8 & 49 \\
$\begin{array}{l}\text { Partial specific volume } \\
\left(\bar{\nabla} \text { at } 20^{\circ} \mathrm{C}\right)\end{array}$ & 0.75 & 075 & 075 \\
$\begin{array}{l}\text { Sedimentation constant } \\
\left(s_{20, \mathrm{w}}^{0}\right)\end{array}$ & 3.7 & 3.7 & 39 \\
$\begin{array}{l}\text { Molecular weight }{ }^{b} \\
\text { Molecular weight } \\
\text { of subunits }\end{array}$ & $52,000 \pm 2000$ & - & $55,000 \pm 2000$ \\
& $5000 \pm 1000$ & $5000 \pm 1000$ & $5000 \pm 1000$ \\
& $(6000 \pm 1000)$ & $(6000 \pm 1000)$ & $8000 \pm 16 \mathrm{C} 0$ \\
& $20,000 \pm 1000$ & $20,000 \pm 1000$ & $20,000 \pm 1000$ \\
& & & $26,000 \pm 1300$ \\
\hline
\end{tabular}

a Values in parentheses were obtained from the amino acid analysis.

$b$ Values were obtained from sedimentation equilibrium study.

c Values in parentheses were obtained from gel filtration in $7 \mathrm{~m}$ urea, and all others were estimated from SDS-PAGE.

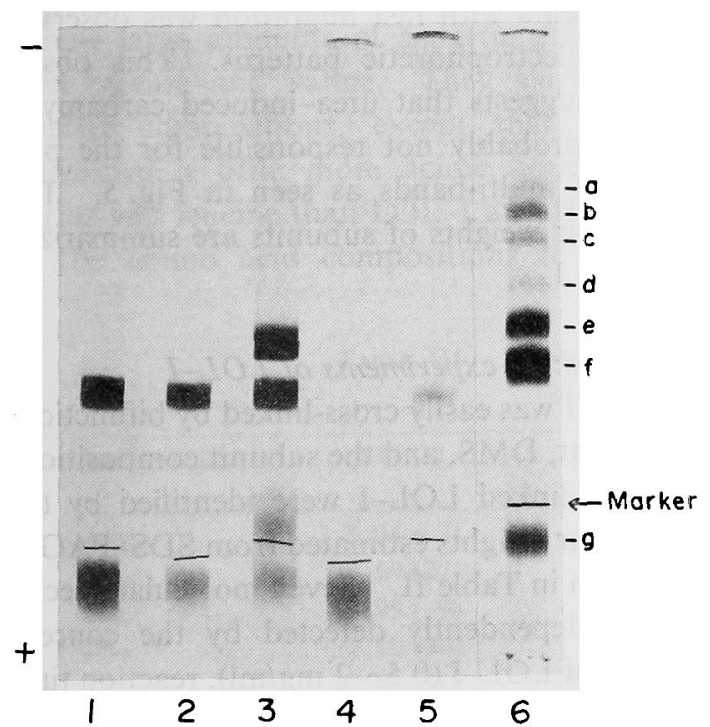

FIG. 4. Polyacrylamide Gel Electrophoresis of LOLI, II and III in the Presence of $0.1 \% \mathrm{SDS}$.

(1) LOL-I, (2) LOL-II, (3) LOL-III, (4) the a subunit of LOL-I, (5) the $\beta$ subunit of LOL-I, (6) c:oss-linked LOL-I.

PAGE are shown in Figs. 4 and 5. The results of SDS-PAGE suggest that three lectins isolated here are oligomeric structures which consist of two types differing in size, large and small polypeptide chains. The SDS-PAGE analysis of LOL-I gave a molecular weight of

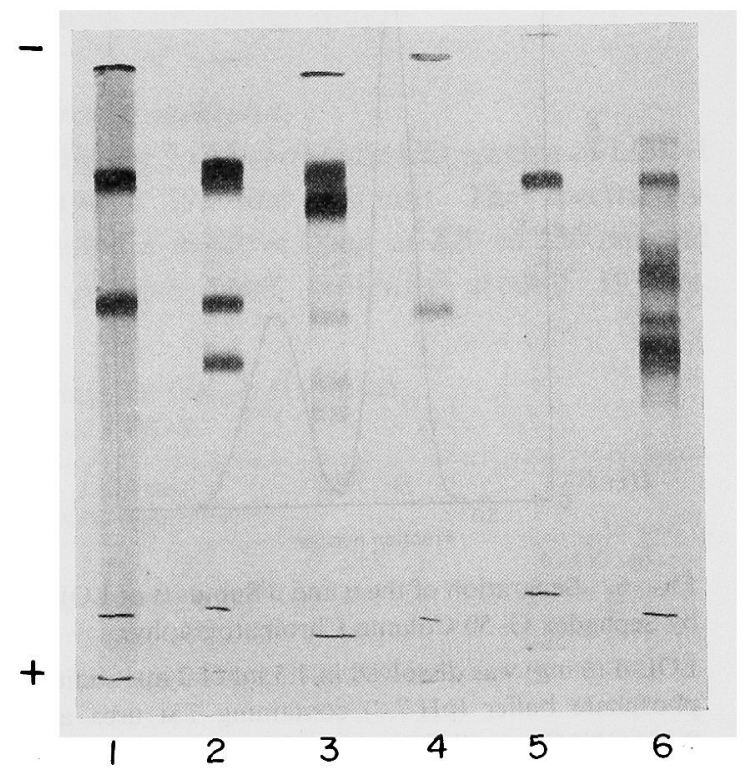

FIG. 5. Polyacrylamide Gel Electrophoresis of LOLI, II and III in the Presence of $8 \mathrm{~m}$ Urea.

(1) LOL-I, (2) LOL-II, (3) LOL-III, (4) the $\alpha$ subunit of LOL-I, (5) the $\beta$ subunit of LOL-I, (6) a typical gel of LOL-I treated with potassium cyarate.

$20,000 \pm 1000$ for the large subunit in the 5 $10 \%$ gels and $5000 \pm 1000$ for small subunit in the $12.5 \%$ gel. The molecular weight of $6000 \pm 1000$ was obtained for the small subunit by gel filtration. This value was considered more reliable than that obtained by SDS- 
PAGE, because there are some doubts about molecular weights less than 10,000 determined by SDS-PAGE. ${ }^{11}$ Each subunit was isolated by gel chromatography in $2 \mathrm{~mm}$ sodium phosphate buffer ( $\mathrm{pH} 7.0$ ) containing $7 \mathrm{M}$ urea and $0.15 \mathrm{M} \mathrm{NaCl}$ on Sephadex G-50 column (Fig.6). The extinction coefficient at $280 \mathrm{~nm} E_{1 \mathrm{~cm}}^{1 \%}$, in $7 \mathrm{M}$ urea solution of each subunit was determined to be 20.6 for the small subunit ( $\alpha$ subunit) or 15.2 for the large subunit ( $\beta$ subunit). On this basis, the weight ratio of the $\beta$ to the $\alpha$ subunit existing in LOL-I was determined to be nearly 3 to 1 from the peak areas of Fig. 6, which corresponded to 1 to 1 on a molar basis.

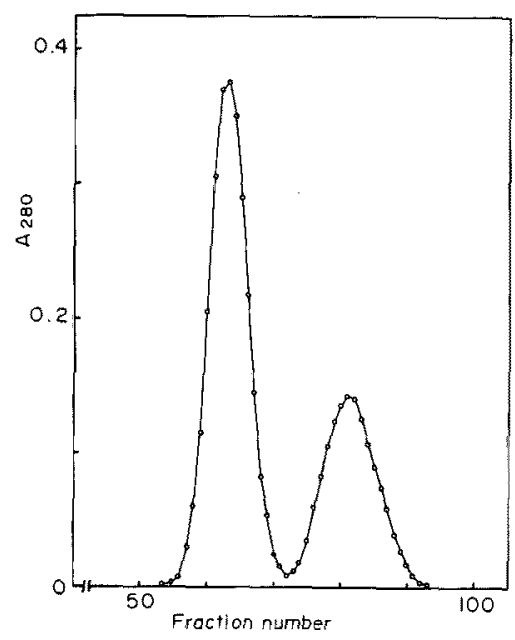

FIG. 6. Separation of the $\alpha$ and $\beta$ Subunits of LOL-I by Sephadex G-50 Column Chromatography.

LOL-I $(6 \mathrm{mg}$ ) was dissolved in $1.5 \mathrm{ml}$ of $2 \mathrm{~mm}$ sodium phosphate buffer (pH 7.0) containing $7 \mathrm{M}$ urea and $0.15 \mathrm{M} \mathrm{NaCl}$, applied to a Sephadex G-50 column $(2.2 \times 90 \mathrm{~cm})$ and eluted with the same buffer at $4^{\circ} \mathrm{C}$. The flow rate was $15 \mathrm{ml} / \mathrm{hr}$, and the volume of fractions was $2.5 \mathrm{ml}$.

LOL-II and III showed more complicated electrophoretic profiles (Fig. 5) than LOL-I. LOL-II gave the same elution profile on gel filtration in $7 \mathrm{M}$ urea and the same migration mobilities on SDS-PAGE as LOL-I. However, the result of $8 \mathrm{M}$ urea-PAGE apparently indicated that LOL-II, unlike LOL-I, had four different molecular species, but each of two pairs among these four species had an identical molecular weight. LOL-III showed four bands in SDS-PAGE corresponding to the molecular weights of $26,000 \pm 1300,20,000 \pm 1000$, $8000 \pm 1600$ and $5000 \pm 1000$, while six bands appeared in $8 \mathrm{M}$ urea-PAGE.

The formation of cyanate in urea solution has long been recognized, and it has been known that the carbamylation of proteins may occur, thus leading to heterogeneity of an artifactual nature. ${ }^{19,20)}$ To examine the carbamylation of LOL-I, II and III, the three lectins were incubated in highly concentrated solutions of potassium cyanate under various conditions and were analyzed by $8 \mathrm{M}$ urea-PAGE. The bands in the gel (Fig. 5(6)) do not necessarily correspond to those in other gels, because electrophoresis was not run at the same time. However, the split of the bands into several components with fast migration was observed in the electrophoretic patterns. This observation suggests that urea-induced carbamylation is probably not responsible for the presence of multi-bands as seen in Fig. 5. The molecular weights of subunits are summarized in Table I.

\section{Cross-linking experiments of $L O L-I$}

LOL-I was easily cross-linked by bifunctional reagent, DMS, and the subunit compositions of cross-linked LOL-I were identified by the molecular weights estimated from SDS-PAGE, as shown in Table II. Seven molecular species were independently detected by the concentration of LOL-I $(0.5 \sim 2 \mathrm{mg} / \mathrm{ml})$, reaction time $(1 \sim 3 \mathrm{hr})$ and temperature $\left(4\right.$ and $\left.25^{\circ} \mathrm{C}\right)$. These observations suggest that these species are formed by intramolecular cross-linking, and the results are consistent with the finding that LOL-I is composed of two $\alpha$ subunits and two $\beta$ subunits.

In SDS-PAGE, the band corresponding to the $\alpha_{2}$ species was not detected. This is considered to be caused by steric hindrance or higher reactivity of $\alpha-\beta$ cross-linking than $\alpha-\alpha$ cross-linking, since the only reaction sites are two lysine residues on the $\alpha$ subunit. 
Table II. Molecular Weights and Proposed Subunit Compositions of Oligomeric Species Produced by Cross-Linking LOL-I WITH Dimethyl Suberimidate

\begin{tabular}{cccc}
\hline Band & $\begin{array}{c}\text { Observed } \\
\text { Molecular weight } \\
\text { composition }\end{array}$ & $\begin{array}{c}\text { Proposed } \\
\text { Subunit } \\
\text { colative } \\
\text { yield }^{a}\end{array}$ \\
\hline a & $50,000 \pm 2500$ & $\alpha_{2} \beta_{2}$ & 1.0 \\
b & $47,000 \pm 2400$ & $\alpha \beta_{2}$ & 3.5 \\
c & $40,000 \pm 2000$ & $\beta_{2}$ & 2.0 \\
d & $30,000 \pm 1500$ & $\alpha_{2} \beta$ & 0.9 \\
e & $26,000 \pm 1300$ & $\alpha \beta$ & 10.0 \\
f & $20,000 \pm 1000$ & $\beta$ & 19.8 \\
g & $<10,000$ & $\alpha$ & 8.4 \\
\hline a Yield is relative to band a. &
\end{tabular}

\section{Composition}

Table III shows amino acid compositions of LOL-I, II and III and the $\alpha$ and $\beta$ subunits of LOL-I. A characteristic feature was that these lectins had no methionine or cysteine, and contained large amounts of aspartic acid, threonine, serine and valine. They showed very similar compositions, except that LOL-III contained a little more acidic amino acids, serine and leucine than LOL-I and II.

The amino acid compositions of the two subunits of LOL-I showed significant differences; the $\beta$ subunit contained more aspartic acid and isoleucine and less glutamic acid, serine and valine than the $\alpha$ subunit on a mole percentage basis. The amino acid compositions of LOL-I and its subunits are again in accord with an $\alpha_{2} \beta_{2}$ subunit structure for LOL-I.

Amino sugar was not detected. Small amounts of neutral sugar, less than $0.2 \%$ on a weight basis, were detected for all lectins by the phenol-sulfuric acid method. The component of the neutral sugar was identified as D-glucose by gas chromatography, and its amounts were less than one molecule of $D$ glucose bound per molecule of the protein. It is therefore likely that this sugar was contaminated during the preparation of lectin by affinity chromatography.

\section{Circular dichroism}

Figure 7 (A) shows the CD spectra of LOL-1 between 195 and $250 \mathrm{~nm}$. The spectra exhibited a negative band at 220 to $230 \mathrm{~nm}$ and a positive band centering around $197 \mathrm{~nm}$.

Table III. Amino Acid Compositions of LOL-I, II AND III AND THE Subunits of LOL-I

\begin{tabular}{|c|c|c|c|c|c|}
\hline Amino acid & LOL-I & $\alpha$-Subunit & $\begin{array}{c}\beta \text {-Subunit } \\
\mathrm{mol} / \mathrm{mol} \text { of protein }\end{array}$ & LOL-II & LOL-III \\
\hline Arg & $7.04(7)$ & $1.07(1)$ & $2.60(3)$ & $7.22(7)$ & $6.46(6)$ \\
\hline Lys & $26.69(27)$ & $2.42(2)$ & $11.53(12)$ & $25.48(25)$ & $24.96(25)$ \\
\hline His & $8.99(9)$ & $2.30(2)$ & $2.89(3)$ & $8.93(9)$ & $8.98(9)$ \\
\hline Phe & $34.12(34)$ & $2.70(3)$ & $12.61(13)$ & $32.48(32)$ & $34.98(35)$ \\
\hline Tyr & $17.84(18)$ & $0.98(1)$ & $7.52(8)$ & $18.62(19)$ & $18.88(19)$ \\
\hline Leu & $26.71(27)$ & $4.52(5)$ & $9.33(9)$ & $26.82(27)$ & $31.54(32)$ \\
\hline Ile & $24.84(25)$ & $1.25(1)$ & $10.93(11)$ & $24.69(25)$ & $27.13(27)$ \\
\hline Met & - & - & - & - & - \\
\hline Val & $44.98(45)$ & $6.85(7)$ & $16.14(16)$ & $48.34(48)$ & $48.35(48)$ \\
\hline Cys & - & - & - & - & - \\
\hline Ala & $38.34(38)$ & $4.53(5)$ & $13.71(14)$ & $39.60(40)$ & $38.02(38)$ \\
\hline Gly & $38.53(39)$ & $5.68(6)$ & $13.63(14)$ & $40.17(40)$ & $39.67(40)$ \\
\hline Pro & $21.56(22)$ & $2.72(3)$ & $7.14(7)$ & $21.02(21)$ & $21.56(22)$ \\
\hline Glu & $32.95(33)$ & $6.44(6)$ & $10.22(10)$ & $31.52(32)$ & 38.75 (39) \\
\hline Ser & $47.08(47)$ & $8.46(8)$ & $16.88(17)$ & $46.23(46)$ & $50.95(51)$ \\
\hline Thr & $54.30(54)$ & $5.49(5)$ & $21.65(22)$ & $54.22(54)$ & $57.22(57)$ \\
\hline Asp & $62.72(63)$ & $2.55(3)$ & $28.91(29)$ & $63.20(63)$ & $67.23(67)$ \\
\hline
\end{tabular}

a Molecular weights: LOL-I and II, $52000 ; \alpha$ subunit, $6000 ; \beta$ subunit, 20,000; LOL-III, 55,000 .

b Tryptophan was not determined.

c Values in parentheses indicate the numbers of residues expressed in the nearest whole integer. 
Similar spectra were also obtained for LOL-II and III. The CD spectrum resembles that of poly-S-carboxymethyl-L-cysteine which was folded into an anti-parallel $\beta$-pleated sheet, ${ }^{21,22\}}$ and that of Con $A$ which was shown to have $\beta$-structure by X-ray studies. ${ }^{23,247}$ No trough

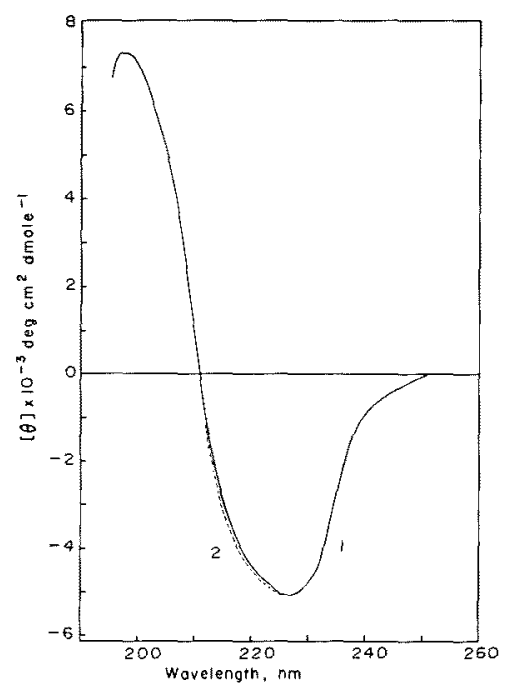

(A)

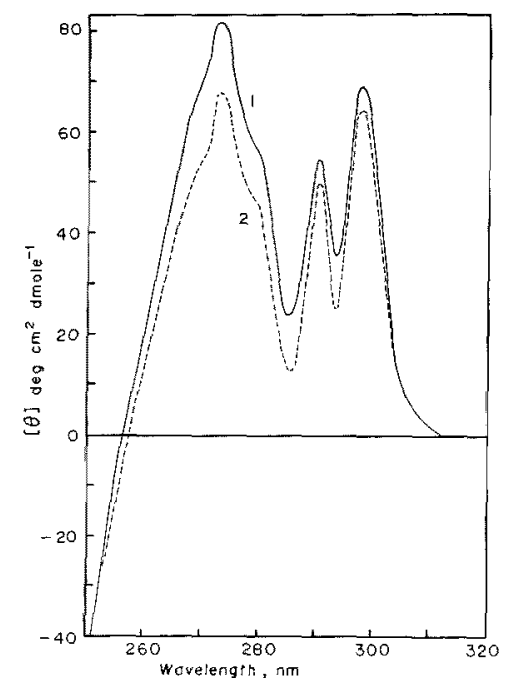

(B)

Fig. 7. Circular Dichroism Spectra of LOL-I.

Far ultraviolet (A) and near ultraviolet (B) CD spectra of LOL-I, (1) _-, spectrum in the absence of a-methyl D-mannoside, (2) ------, spectrum in the presence of $0.05 \mathrm{~m} \alpha$-methyl D-mannoside. The spectra were taken in $0.1 \mathrm{M} \mathrm{KCl}, 2 \mathrm{~mm}$ sodium phosphate buffer, pH 7.0. or shoulder could be discerned in the region of $209 \mathrm{~nm}$, indicating the absence of appreciable $\alpha$-helical conformation. ${ }^{25)}$ The spectrum appears unambigious in assigning the major secondary structure of the lectin as that of $\beta$-structure. The addition of $\alpha$-methyl $\mathrm{D}$ mannoside which was a strong inhibitor to agglutinating activity of LOL did not result in any change in the secondary structure of the protein.

The near-ultraviolet CD spectra of LOL-I in the presence or absence of $\alpha$-methyl $D$ mannoside are shown in Fig. 7 (B). Significant effects of the saccharide were observed between $260 \sim 300 \mathrm{~nm}$. D-galactose, which did not interact with LOL-I (see Table IV), had no effect on its CD spectrum. Since $\alpha$-methyl $\mathrm{D}$-mannoside had no absorption bands in the regions examined in this study and LOL-I contains no disulfide bonds, it appears that the optical activity differences caused by the binding of $\alpha$-methyl D-mannoside by lectin reflect changes in the environment of tyrosine and tryptophan residues.

Inhibition of agglutination with various sugars

In Table IV are given the results of inhibition tests of agglutination of chicken erythrocytes with sugars on LOL-I, II and III. The three components had the identical specificity under the conditions of assay, and $\alpha$ -

Table IV. InhibItion Assay of LOL-I, II AND IIl WITH SUGars ${ }^{a}$

\begin{tabular}{|c|c|c|c|}
\hline \multirow{2}{*}{ Sugar } & \multicolumn{3}{|c|}{$\begin{array}{c}\text { Minimum amounts }(\mathrm{mg} / \mathrm{ml}) \\
\text { inhibiting four } \\
\text { hemagglutinating doses }\end{array}$} \\
\hline & LOL-I & LOL-II & I LOL-III \\
\hline$\alpha$-Methyl D-mannoside & 0.63 & 0.63 & 0.63 \\
\hline D-Mannose & 1.25 & 1.25 & 1.25 \\
\hline D-Glucose & 2.5 & 2.5 & 2.5 \\
\hline$N$-Acetyl-D-glucosamine & 5.0 & 5.0 & 5.0 \\
\hline D-Galactose & $>10$ & $>10$ & $>10$ \\
\hline \multicolumn{4}{|c|}{$N$-Acetyl-D-galactosamine } \\
\hline & $>10$ & $>10$ & $>10$ \\
\hline D-Xylose & $>10$ & $>10$ & $>10$ \\
\hline L-Fucose & $>10$ & $>10$ & $>10$ \\
\hline
\end{tabular}

a Assay was done with erythrocytes from laying hen. 
methyl D-mannoside was the most powerful inhibitor to the agglutination among the sugars investigated here in. The specificity for monosaccharide of LOL showed an analougous trend to that of other D-mannose specific lectins such as Con A, Lens culinaris lectin and Pisum sativum lectin. ${ }^{26 \sim 299}$

\section{Binding of D-mannose to LOL-I}

Binding of D-mannose to LOL-I was examined by equilibrium dialysis at $4^{\circ} \mathrm{C}$. Experiments performed with $20 \mathrm{mg} / \mathrm{ml}$ of LOL-I gave barely detectable binding, and the aggregation of protein was apparently observed during the dialysis experiments at an LOL-I concentration of $60 \mathrm{mg} / \mathrm{ml}$. Furthermore, an apparent decrease in binding was observed with an increase in ligand concentration above $2 \mathrm{mM}$ (protein concentration $10 \sim 40 \mathrm{mg} / \mathrm{ml}$ ), and this phenomenon is thermodynamically inadmissible. A conceivable cause is an aggregation of protein, following the loss of binding ability.

Because of these experimental limitations, reliable binding studies were possible only at

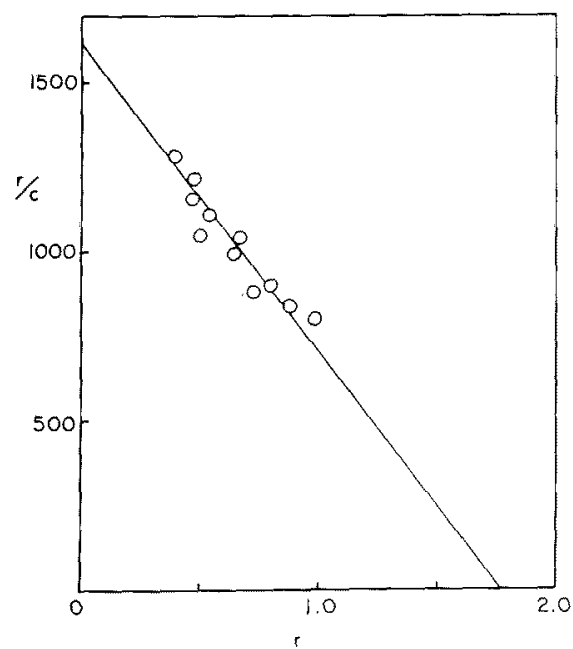

FIG. 8, Binding of D-mannose to LOL-I.

The results are plotted according to Scatchard equation, $r / c=n K-r K$, in which $r$ is the number of molecules of sugar bound per molecule of LOL-I- $c$ is the molar concentration of free sugar; $n$ is the maximal value for $r$, and $K$ is the association constant (liters per mol).
Table $V$. Hemagglutinating Activities of LOL-I, II AND III AND CONCANAVALIN A AGAINST THREe TyPes OF ERYTHROCYTES FROM CHICKEN ${ }^{a}$

\begin{tabular}{lrcc}
\hline \multirow{2}{*}{ Lectin } & \multicolumn{3}{c}{ Titer of $1 \%$ lectin solution } \\
\cline { 2 - 4 } & $\begin{array}{c}\text { Laying } \\
\text { hen }\end{array}$ & $\begin{array}{c}\text { Nonlaying } \\
\text { hen }\end{array}$ & Male \\
\hline LOL-I & 2048 & - & - \\
LOL-II & 2048 & - & - \\
LOL-III & 2048 & - & - \\
Con A (tetramer) & 256 & 256 & 256 \\
Con A (dimer) & 64 & 64 & 64 \\
\hline
\end{tabular}

a Activities were assayed in phosphate-buffered saline under the following conditions: LOL-I, II and III, $\mathrm{pH} 7.2,4^{\circ} \mathrm{C}$; Con A (tetramer), $\mathrm{pH} \mathrm{7.2,}$ $20^{\circ} \mathrm{C}$; Con A (dimer), $\mathrm{pH} 6.2,4^{\circ} \mathrm{C}$.

$b$ Assay was done in a lectin concentration of $1.25 \mathrm{mg} / \mathrm{ml}$ (titer 8 ).

a lectin concentration of up to $40 \mathrm{mg} / \mathrm{ml}$ and at a ligand concentration of less than $1 \mathrm{~mm}$. Figure 8 shows a Scatchard plot of such experiments. Though a long extrapolation to the abscissa remains uncertain, the result suggests that there are two binding sites per molecule of LOL-I for D-mannose, and that the association constant is about 1000 liters per mole.

Agglutinating activities against erythrocytes from chicken

Table $\mathrm{V}$ shows the agglutinating activities of LOL-I, II and III against three kinds of erythrocytes derived from laying hen, non-laying hen and male. In the table, for a comparative purpose, are also included data on Con A of which the sugar binding capacity was found similar to LOL. LOL reacted only with erythrocyte from laying hen, and did not show any detectable difference in activity. In contrast, Con A reacted with all types of erythrocytes from chicken. The diminished ability of Con $\mathrm{A}$ at $\mathrm{pH} 6.2$ could be explained by the dissociation of the protein into the dimer form. ${ }^{301}$

\section{DISCUSSION}

Affinity-purified Lathyrus odoratus lectin is, 
at least, a mixture of three molecular species. These species are electrophoretically distinguishable in aqueous media, but are the same in agglutinating activity for the erythrocytes of chickens and in sugar specificity for the inhibition of agglutination. The molecular structure of the major component, LOL-I, of which about two-thirds consisted of LOL, was studied in detail.

The experimental data show that LOL-I is a tetrameric molecule consisting of two $\alpha$ and two $\beta$ chains. The estimated molecular weights of the native LOL-I $(52,000 \pm 2000$ from sedimentation equilibrium study), the $\alpha$ subunit $(6000 \pm 1000$ from chromatography in $7 \mathrm{M}$ urea; $5000 \pm 1000$ from SDS-PAGE) and the $\beta$ subunit $(20,000 \pm 1000$ from SDS-PAGE) endorse the above model. The results of SDS-PAGE, $8 \mathrm{M}$ urea-PAGE, gel chromatography in $7 \mathrm{M}$ urea, and the amino acid compositions of native LOL-I and the isolated subunits demonstrate that LOL-I contains two types of subunits in a ratio of about $1: 1$ on a molar basis. This model well agrees with the results obtained from the cross-linking study with DMS.

The results of SDS-PAGE, $8 \mathrm{M}$ urea-PAGE and gel chromatography in $7 \mathrm{M}$ urea suggest that LOL-II have a very similar assembly of subunits to LOL-I. The estimated molecular weights of native LOL-III $(55,000 \pm 2000$ from sedimentation equilibrium study) and the subunits $(26,000 \pm 1300,20,000 \pm 1000,8000 \pm 1600$ and $5000 \pm 1000$ from SDS-PAGE) suggest that LOL-III is a tetramer having two large and two small molecular species. It is obvious, however, that LOL-II has subunit species which are the same in size but differ in charge, as revealed by SDS and $8 \mathrm{M}$ ureaPAGE. This also is the case with LOL-III. Accordingly there is a possibility that each of LOL-II and III, especially LOL-III, is not a single species of protein but a mixture of protein molecules which are similar in molecular size and charge, though both lectins showed a single band in isoelectric focusing and disc gel electrophoresis. No further attempt was made to examine whether LOL-II and III obtained by DEAE-cellulose chromatography were homogeneous proteins.

The amino acid compositions of LOL-I, II and III are similar to those of a number of other reported lectins in that they have large threonine and aspartic acid, but little or no methionine and half-cystine contents. ${ }^{31 \sim 36)}$ Virtually LOL is devoid of covalently bound sugar.

The present study has demonstrated that $\beta$ structure is the major ordered structure of LOL. It is noteworthy that CD data reported so far have indicated the presence of $\beta$-structure as the major ordered structure of many lectins. ${ }^{23,37 \sim 40)}$ Such conformational studies including the present one have shown that $\beta$-structure is not affected when the lectins bind specific sugars. This general feature suggests that $\beta$-structure may not be a part of the sugar binding site but may be located in another region of the molecule. As evidenced in Con A by X-ray crystallographic studies, ${ }^{24}$. it is possible that $\beta$-structure in a lectin molecule may play an important role in the formation of oligomer which is a prerequisite for the functions of lectin such as the agglutination of cells.

Although the sugar specificity of LOL-I to monosaccharide was practically similar to that of Con A, different agglutinating abilities of LOL were observed against three kinds of chicken erythrocytes. There will be no possibility that this discrepancy between LOL and Con A results from the differences in molecular proterties of the lectins: saccharide binding constant, number of binding site and molecular size. For instance, Con $\mathrm{A}$ exists in the dimer at $\mathrm{pH} 6.2,4^{\circ} \mathrm{C},{ }^{30}$ and the molecular weight and the number of binding sites are essentially the same as those of LOL-I. The similarity in such properties cannot account for the reason why Con A has the same ag. glutinating ability against three kinds of chicken erythrocytes, while LOL can agglutinate only the erythrocyte from laying hens. It is more likely that LOL and Con A have different specificities against carbohydrate chain on the surface of erythrocyte from 
chicken. The existence of subtle differences in specificity among D-mannose specific lectins has been reported. ${ }^{41,42)}$

The results of Table $\mathrm{V}$ suggest that some changes are occurring in the surface of chicken erythrocyte associated with egg production. Obviously, cell agglutination is a highly complex process, and the properties of a cell which affect the agglutination include several factors: for example, cell rigidity, the metabolic state of the cell, and the number of lectin receptor sites, their distribution and their mobility in the membrane. However, most properties of the chicken erythrocyte and its surface are highly obscure. The use of LOL with other lectins will help elucidate the properties of the lectin receptor and the cell surface structure which is essential for understanding the mechanism of the different agglutinating behaviors observed in this experiment.

Acknowledgment. The authors thank Dr. K. Kondo of Nagoya University and Dr. M. Mizutani of NIBS Laboratory animal research station, Yamanashi, for their valuable advices on this research and $\mathrm{Mr}$. $\mathrm{M}$. Miyajima for providing blood samples.

\section{REFERENCES}

1) I. E. Liener, Ann. Rev. Plant Physiol., 27, 291 (1976).

2) H. Lis and N. Sharon, "The Antigens," Vol. 4, ed. by M. Sela, Academic Press, New York, N. Y., 1977 , p. 429.

3) G. L. Nicolson, Biochim. Biophys. Acta, 458, 1 (1976).

4) S. L. Scheinberg and R. P. Reckel, Poulty Sci., 40, 795 (1961).

5) M. Mizutani and Y. Fujio, Jap. J. Zootech. Sci., 42, 401 (1971).

6) L. L. Chan, Pro. Natl. Acad. Sci. U.S.A., 74, 1062 (1977).

7) R. J. Bause and G. R. Gray, J. Biol. Chem., 252, 57 (1977).

8) L. Ornstein and B. J. Davis, Ann. N. Y. Acad. Sci, 121, 321 (1964).

9) K. Weber and M. Osborn, J. Biol. Chem., 244, 4406 (1969).

10) K. Hayashi, E. Matsutera and Y. Ohba, Biochim. Biophys. Acta, 342, 185 (1974).

11) R. T. Swank and K. D. Munkes, Anal. Biochem., 39, 462 (1971).

12) F. Falcoz-kelly, J. Janin, J. C. Saari, M. Véron,
P. Truffa-Bachi and G. N. Cohen, Eur. I. Biochem., 28, 507 (1972).

13) D. A. Yphantis, Biochemistry, 3, 297 (1964).

14) G. E. Davies and G. R. Stark, Pro. Natl. Acad. Sci. U.S.A., 66, 651 (1970).

15) M. Dubois, K. A. Gilles, J. K. Hamilton, P. A. Rebers and F. Smith, Anal. Chem., 28, 350 (1956).

16) W. Niedermeier, Anal. Biochem., 40, 465 (1971).

17) R. D. Marshall, A. Neuberger, "Glycoproteins," Part A, ed. by A. Gottshalk, Elsevier, Amsterdam, 1972 , p. 224.

18) I. Matsumoto and T. Osawa, Biochim. Biophys. Acta, 194, 180 (1969).

19) J. R. Marier and D. Rose, Anal. Biochem., 7, 304 (1964).

20) E. G. Cole and D. K. Mecham, Anal. Biochem., 14, 215 (1966).

21) L. Stevens, R. Townend, S. N. Timasheff, G. D. Fasman and J. Potter, Biochemistry, 7, 3717 (1968).

22) S. Ikeda and G. D. Fasman, J. Mol. Biol., 30, 491 (1967).

23) M. N. Pflumm, J. L. Wang and G. M. Edelman, J. Biol. Chem., 246, 4369 (1971).

24) J. W. Becker, G. N. Reeke, Jr., J. L. Wang, B. A. Cunningham and G. M. Edelman, J. Biol. Chem. 250, 1513 (1975).

25) Y. H. Chen, J.T. Yang and K. H. Chau, Biochemistry, 13, 3350 (1974).

26) S. Toyoshima, T. Osawa and A. Tonomura, Biochim. Biophys. Acta, 221, 514 (1970).

27) I. K. Howard and H. J. Sage, Biochemistry, 8, 2436 (1969).

28) I. J. Goldstein, C. E. Hollerman and E. E. Smith, Biochemistry, 4, 876 (1965).

29) J. P. Van Wauwe, F. G. Loontiens and C. K. De Bruyne, Biochim. Biophys. Acta, 379, 456 (1975).

30) M. Huet, Eur. J. Biochem., 59, 627 (1975).

31) A. Foriers, C. Wuilmart, N. Sharon and A.D. Strosberg, Biochem. Biophys. Res. Comm., 75, 980 (1977).

32) R. Lotan, E. Skutelsky, D. Danon and N. Sharon, J. Biol. Chem., 250, 8518 (1975).

33) I. S. Trowbridge, J. Biol. Chem., 249, 6004 (1974).

34) I. K. Howard, H. J. Sage, M. D. Stein, N. M. Young, M. A. Leon and D. F. Dyckes, J. Biol. Chem., 246, 1590 (1971).

35) J. L. Wang, B. A. Cunningham, M. J. Waxdal and G. M. Edelman, J. Biol. Chem., 250, 1490 (1975).

36) M. Tichá, G. Entlicher, J. V. Koštiř and J. Kocourek, Biochim. Biophys. Acta, 221, 282(1970).

37) M. Père, R. Bourrillon and B. Jirgensons, Biochim. Biophys. Acta, 393, 31 (1975).

38) J. Lönngren, I. J. Goldstein and R. Zand, Biochemistry, 15, 436 (1976).

39) L. Bureš, G. Entlicher and J. Kocourek, Biochim. Biophys. Acta, 285, 235 (1972). 
40) K. Shimazaki, E. F. Walborg, Jr., G. Neri and B. Jirgensons, Arch. Biochem. Biophys., 169, 731 (1975).

41) R. Kaifu, T. Osawa and R. W. Jeanloz, Carbohyd.
Res., 40, 111 (1975).

42) J. P. Van Wauwe, F. G. Loontiens, H. A. Carchon and C. K. De Bruyne, Carbohyd. Res., 30, 249 (1973). 